\title{
ANALISIS PUTARAN IDEAL BLOWER PADA MESIN PENGUPAS KOPI TIPE HAMMER MILL DENGAN KAPASITAS KUPAS 90 KG PER JAM
}

Oleh :

Febriyanti

Kopi gelondangan yang diterima dari petani mempunyai kadar air $\pm 22 \%$. Kopi gelondongan ini kemudian di proses agat menjadi biji kopi dengan kadar air $\pm 12 \%$. Kopi gelondongan dari petani dimasukkan ke rumah pengering (drying house) yang merupakan bagian dari mesin oven. Mesin oven ini memliki temperatur maksimum $60^{\circ} \mathrm{C}$ dengan suhu uangan $21,2^{\circ} \mathrm{C}$, setelah itu kopi akan dikupas pada mesin pengupas jenis Hammer Mill System yang mempunyai kapasitas $90 \mathrm{~kg} / \mathrm{jam}$.

Penelitian ini merupakan penelitian sesungguhnya (true experiment), hal ini berdasarkan pertimbangan sederhana bahwa penelitian dilaksanakan untuk meneliti puratan ideal blower pada mesin pengupas kopi tipe Hammer mill.

Hasil penelitian sebagai berikut: 1). Putaran blower yang ideal untuk mesin pengupas kopi tipe Hammer mill yaitu 1.576,27 rpm berdasarkan penelitian yang telah dilakukan yaitu terhadap 1000 gram biji dan kulit kopi, maka pada penadahan biji terdapat kulit sebanyak 2 gram sedangkan pada penadah kulit terdapat biji sebanyak 3 gram 2). Kapasitas pengupasan kulit tetap yaiut $90 \mathrm{~kg} / \mathrm{jam}$

3). Dengan berubahnya putaran blower, maka diameter pulli yang digunakan adalah: a. Diameter pulli motor (dp) $300 \mathrm{~mm}$ b. Diameter pulli pemukul (Dp) 221,4 mm c. Diameter pulli pemukul $\left(\mathrm{d}_{2}\right) 93 \mathrm{~mm}$ d. Diameter pulli blower $\left.\left(\mathrm{d}_{3}\right) \quad 118 \mathrm{~mm} \mathrm{4}\right)$. Untuk poros tetap menggunakan yang ada, karena poros tersebut aman digunakan dengan poros yang ada yaitu: a. Diameter poros motor (ds) $18 \mathrm{~mm} \mathrm{~b}$. Diameter poros pemukul $\left(\mathrm{ds}_{2}\right) 25 \mathrm{~mm} \mathrm{c}$. Diameter poros blower $\left(\mathrm{d}_{\mathrm{s} 3}\right) 20 \mathrm{~mm}$.

Kata Kunci: Ideal Blower, Mesin Pengupas Kopi, Hammer Mill, Kapasitas Kupas

\section{PLAYER ANALYSIS IDEAL BLOWER ON THE COFFEE MACHINE OF HAMPHILL MILL TYPE WITH COTTON 90 KG PER HOUR}

By:

Febriyanti

Coffee receipt received from farmers has water content $\pm 22 \%$. Coffee spindle is then in the process into coffee beans with water content $\pm 12 \%$. The logs from the farmers are fed into the drying house which is part of the oven machine. This oven machine has a maximum temperature of $60^{\circ} \mathrm{C}$ with a temperature of $21.2^{\circ} \mathrm{C}$, after which the coffee will be peeled on Hammer Mill System type peeler which has a capacity of $90 \mathrm{~kg} / \mathrm{hour}$.

This study is a true experiment, it is based on the simple consideration that the research was conducted to investigate the ideal blower ideal for Hammer Mill type coffee exchangers.

The results of the study as follows: 1). The ideal blower rotation for Hammer mill type peel machine is 1,576,27 rpm based on research that has been done that is to 1000 gram of seeds and skin of coffee, hence on the grading of seeds there are skin as much as 2 gram whereas in skin container there are 3 gram of seed 2). The capacity of peeling skin remains $90 \mathrm{~kg}$ / hour 3). By changing the blower rotation, the diameter of the pulley used is: a. Diameter of motorcycle pulp (dp) $300 \mathrm{~mm} \mathrm{~b}$. Diameter of the hammer pulp (Dp) 
$221.4 \mathrm{~mm} \mathrm{c}$. Diameter of hammer pulper (d2) $93 \mathrm{~mm} \mathrm{~d}$. Diameter of blower pulp (d3) 118 $\mathrm{mm} 4$ ). For a fixed shaft using the existing, because the shaft is safe to use with the existing axis that is: a. Motor shaft diameter (ds) $18 \mathrm{~mm} \mathrm{~b}$. Diameter of hammer shaft (ds2) $25 \mathrm{~mm}$ c. Diameter of blower shaft (ds3) $20 \mathrm{~mm}$.

Keywords: Ideal Blower, Coffee Peeler, Hammer Mill, Peel Capacity

\section{Pendahuluan}

\subsection{Latar Belakang}

Biji kopi merupakan komoditas ekspor yang cukup tinggi dan mempunyai nila jual yang cukup baik. Namun semua iru tergantung pada kualitas biki kopinya. Proses pengerjaan dari kopi gelondongan (masih berkulit) menjadi biji kopi sangat berpengaruh terhadap kualitas kopi. Kopi gelondangan yang diterima dari petani mempunyai kadar air $\pm 22 \%$. Kopi gelondongan ini kemudian di proses agat menjadi biji kopi dengan kadar air \pm 12 $\%$. Kopi gelondongan dari petani dimasukkan ke rumah pengering (drying house) yang merupakan bagian dari mesin oven. Mesin oven ini memliki temperatur maksimum $60^{\circ} \mathrm{C}$ dengan suhu uangan $21,2^{\circ} \mathrm{C}$, setelah itu kopi akan dikupas pada mesin pengupas jenis Hammer mill System yang mempunyai kapasitas $90 \mathrm{~kg} / \mathrm{jam}$.

Dari mesin ini dilanjutkan pada mesin pemoles dimana biji kopi yang sudah dikupas akan dihilangkan kulit ari (lapisan tipis pada biji) oleh mesin tersebut. Proses sortasi merupakan proses pemilihan ukuran biji kopi dan terakhir mesin pemilih biji kopi berdasarkan wana hitam dan coklat dari kopi itu sendiri. Proses pengupasan memakan waktu yang cukup lama karena adanya pemusahan antara kulit kopi dan biji kopi pada mesin pengupasan kopi ini yang kurang sempurna dimana kulit kopi dan biji kopi masih banyak bercampur dipenadah masing-masing, sedangkan waktu proses mempengaruhi efisiensi proses tersebut.

\subsection{Permasalahan}

Berdasarkan latar belakang diatas pada mesin pengupas kopi tipe Hammer mill mempunyai kelemahan yaitu masih banyaknya kulit kopi yang bercampur dengan biji dipenadah biji kopi.

\subsection{Batasan Masalah}

Agar masalah yang dibahas tidak meluas serta didapat kejelasan dari rumusan masalah, maka penulis membatasi masalah yang akan dibahas yaitu meliputi penelitian putaran blower yang ideal, dengan melakukan percobaan pada mesin pengupas kopi tipe Hammer mill dan penelitipun hanya membahas pada proses 
pemisahan biji dan kulit kopi saja. Sedangkan poses penggilingan/ pemecahan kopi tidak dibahas.

\subsection{Tujuan dan Manfaat Penelitian}

Penelitian ini dilakukan dengan tujuan, yaitu menguji dan mencari cara mengatasi biji kopi kopi dan kulit kopi yang belum sesuai yang diharapkan dalam hal ini masih banyaknya kulit kopi yang bercampur dengan biji kopi di penadah biji kopi dan penadah kulit kopi.

\subsection{Kerangka Pemikiran}

Kopi merupakan salah satu komoditas ekspor andalan Indonesia, akan tetapi kualitas dari kopi itu sendiri masih belum sesuai dengan keinginan negara pengimpor. Salah satu yang mempengaruhi rendahnya kualitas kopi dikarenakan para pengusaha kopi masih belum menyadari akan pentingnya mesin pengupas kopi olahan. Terlihat dari kualitas hasil yang diperolehmesin pengupas kebanyakan masih belum dapat memenuhi keinginan tersebut serta dengan ilmu pengetahuan seadanya. Pengupasan kopi yang dilakukan oleh para petani masih menggunakan caacaratradisional seperti dengan jalan penumbukan. Sementara alat yang bekerja secara modern telah digunakan oleh para pengusaha kopi masih belum dapat memisahkan biji dan kulit kopi dengan baik. Melihat kondisi demikian yang dialami oleh para petani dan pengusaha tersebut, perlu dianalisa dan diteliti tentang mesin pengupas kopi yang dapat merealisasikan keinginan pata petani dan pengusaha yaitu memperkecil bercampurnya kulit dan biji pada masingmasing penadah.

Mesin ini diharapkan dapat berguna dengan baik meningkatkan mutu kopi rakyat $m$ enjadi kualitas ekspor dan mesin ini juga diharapkan : (a) Biji kopi dapat langsung dipisahkan dari kulit kopi dan kotoran, (b) Mesin tidak memerlukan ukuran perawatan besar, (c) Suku cadang mudah didapat dan diganti karena keseluruhannya diproduksi didalam negeri, (d) Mempunyai efisiensi daya kerja yang tinggi, ekonomis, tenaga yang diperlukan sangat kecil dibandingkan hasil yang dicapai.

\subsection{Hipotesis}

Kecepatan udara blower yang menghisap kulit kopi kecil, sehingga masih banyak kulit yang ikut biji kopi ke penadah biji, disamping itu kapasitas pemisahan yang terlalu banyak menyebabkan terjadi penumpukan biji dan kulit kopi di corong penghisap. 


\section{BAB II. LANDASAN TEORI}

\section{1. Blower}

Blower adalah alat pemindah dan pemanfaatan udara dengan tekanan hingga 2,5 atm. Blower juga dapat memindahkan udara dari suatu ruangan keruangan lain, misalnya ada pengeringan bahan yang menggunakan hembusan udara.

\section{2. Pemilihan Jenis - Jenis Blower}

\subsubsection{Blower Sirrocco}

Pada jenis blower sirrocco paling banyak digunakan dalam penyegaran udara seperti digunakan pada unit pengolahan udara dan unit koil kipas udara dan blower sirrocco tersedia dalam jenis isap dan buang untuk keperluan ventilasi mekanikal. Perubahan volume aliran udara dan daya relatif besar. Bentuk konstruksi dan blower jenis penghisap tunggal. Impeller dari blower sirrocco dibuat dari banyak daun sudu yang sempit dan melengkung kedapan searah dengan putaran impeller, daun sudu tersebut dikelilingi atau dales ppelat sisi yang dilekatkan pada poros.

\subsubsection{Blower Beban Terbatas}

Pada blower beban terbatas volume aliran udara, rendah dan perubahan daya relatif rendah disekitar daerah efisiensi maksimum. Konstruksinya berbentuk $\mathrm{S}$ dan melengkung kebelakang pengarah sehingga udara masuk akan berputar mengikuti putaan pada bagian ujungnya. Sudutnya terbuat dari pelat baja, yang bertambah pendek pada bagian yang menjauhi pelat sisi yang berputar, sehingga membentuk keucut.

Bentuk rumah serupa dengan bentuk blower sirrocco, tetapi berukuran relatif lebih besar untuk volume aliran udara yang sama. Pada bagian masuk dipasang 10 sampai 12 buah impeller.

\subsubsection{Blower Pelat}

Blower ini bekerja dengan sudut pelat datar yang disusun dalam arah radial. Konstruksinya sudu sederhana, kuat dan tahan terhadap udara kotor

\subsubsection{Blower Turbo}

Untuk penyegaran udara yang memerlukan kecepatan udara yang tinggi diperlukan blower yang memberikan tekanan statistik yang tinggi dengan tingkat kebisingan yang rendah. Blower tersebut termasuk dalam jenis impeller sentrifungal dengan daun sudu melengkung dan dilas atau dikelilingi pelat sisi yang dipasangkan dengan kokoh pada poros. 


\subsubsection{Blower Air Foil}

Blower ini adalah sejenis kipas turbo dan digunakan untuk memberikan tekanan statik yang tinggi pada volume aliran udara yang besar dan efisiensinya tinggi dan tingkat kebisingan rendah.

Sudut berpenampang air foil dibuat dari baja tuang atau alumunium tuang, berjumlah antara 8 sampai 16 buah. Rumah kipas mirip dengan rumah kipas turbo, dengan lubang masuk yang berbentuk lonceng sehingga memberikan efek aerodinamik yaitu: mengurangi tahan aliran masuk.

\subsubsection{Blower Aliran Melintang}

Impeller dan blower lebih panjang dari pada impeller blower sirrocco dengan daun sudu melengkung kedepan. Pada kedua sisi impeller terdapat pelat sisi yang terpasang pada poros-poros yang ditumpu oleh bantalan pada kedua sisinya, dimana pada salah satu sisi terdapat motor listrik.

Aliran udara terjadi pada kebanyakan impeller yang panjang. Blower ini sangat cocok untuk digunakan pada saluran berpenampang segi panjang yang sempit, dengan tekanan statik yang rendah. Digunakan untuk keperluan tirai udara dan unit koil-blower.

\subsubsection{Blower Propoler}

Blower ini merupakan yang paling sederhana, ukuran daun sudunya bemacam-macam jumlah sudu berjumlah antara 2 sampai 8 buah. Pada blower propeler biasanya dipasang gelang gtesioner yang melingkari propeler untuk memperoleh efisien yang lebih tinggi.

\subsubsection{Blower Axial}

Blower axial dirancang untuk menghasilkan volume udara yang besar terhadap tekanan statik yang relatif rendah. Kipas ini bekerja pada kecepatan yang relatif tinggi dan agak gaduh. Sudu impeller terbuat dari pelat baja atau alumunium tuang. Motor penggeraknya dapat terpasang langsung pada poros impeller atau dengan perantara tali kipas. Kipas ini bekerja pada kecepatan yang relatif tinggi dan agak gaduh. Sudu impeller terbuat dari pelat baja atau alumunium tuang. Motor penggeraknya dapat terpasang langsung pada poros impeller atau dengan perantara tali kipas.

\section{3. Transmisi Sabuk-V}

Transimisi sabuk-V merupakan transmisi yang banyak digunakan diperusahanperusahan dan industri, karena konstruksinya yang sederhana, perawatan mudah dan banyak pilihan. Sabuk-V terbuat dari karet dan mempunyai 
penampang trapesium sedangkan untuk intinya digunakan teteron atau katun, rayon dan nylon.

Sabuk-V biasanya digunakan pada jarak sumbu yang lebih pendek dibandingkan dengan sabuk datar. Sabuk-V dibelitkan pada pulii yang berbentuk $\mathrm{V}$, sehingga sabuk bagian yang bersinggungan dengan pulli mengalami lengkungan lebar bagian dalamnya akan bertambah dan gaya gesek pun akan besar dan menghasilkan daya yang besar. Konstruksi dari sabuk-V dapat dilihat dari (lampiran I).. untuk ukuran penampang sbauk- $\mathrm{V}$ dapat dilihat pada (lampiran I).

Dibawah ini diberikan cara merencanakan sabuk-V sesuai dengan diagram

1. Daya Rencana (Pd)

$\mathrm{Pd}=\quad \mathrm{p} \times \mathrm{fc}$

Dimana : pd = Daya rencana rata-rata $(\mathrm{KW})$

$\mathrm{P} \quad=$ Daya Motor $(\mathrm{KW})$

$\mathrm{Fc} \quad=$ Faktor Koreksi 1.2 pada tabel (lampiran)

2. Momen rencana $(\mathrm{T})$ $\mathrm{T}=9,74 \times 10^{5} \cdot \mathrm{pd} / \mathrm{n} \quad(\mathrm{N} . \mathrm{mm})$ Dimana : $\mathrm{n}=$ putaran pilli $(\mathrm{rpm})$

3. Perhitungan diameter poros (ds) $\mathrm{Ds}=\left[5,1 / \partial_{\mathrm{a}} . \text { Kt. Cb.T }\right]^{1 / 3}$
Dimana: Kt = Faktor

Tumbukan

$$
\begin{array}{ll}
\mathrm{Cb} & =\text { Faktor beban lentur } \\
\partial_{\mathrm{a}} & =\text { tegangan geser yang ditentukan }
\end{array}
$$

4. Besarnya daya yang didapat ditransmisikan (po)

- Untuk sabuk standar:

$$
\begin{aligned}
& P o=\left(d p^{n}\right)\left\{\left(C_{1}\left(d p^{n}\right)^{-0,09}\right.\right. \\
& \left.\left(C_{2} / d p\right)-C_{3}\left(d p^{n}\right)^{2}\right\}-C_{2} \times\{1- \\
& \left.\left(1 / c C_{3}\right)\right\}
\end{aligned}
$$

- Untuk sabuk Sempit

Po $=\left(d p^{n}\right)\left\{\left(C_{1}\left(C_{2} / d p\right)-C_{3}\left(d p^{n}\right)^{2}\right.\right.$

- $\left(4\left(\log 10 d p^{n}\right)^{2}\right\}-C_{2} \times\{1-$

$\left.\left.1 / \mathrm{C}_{3}\right)\right\}$

Untuk daya yang ditransmisikan biasanya pada produsen pembuatan dicantumkan guna mempermudah perhitungan:

Dimana: $\mathrm{dp}=$ Diameter pulli kecil (mm)

$\mathrm{N} \quad=$ Putaran pulli (rpm)

$\mathrm{C}=$ Jarak Sumbu $(\mathrm{mm})$

\section{BAB III. METODOLOGI \\ PENELITIAN}

\section{1. Jenis Penelitian}

Penelitian ini merupakan penelitian sesungguhnya (true experiment), hal ini berdasarkan pertimbangan sederhana bahwa penelitian dilaksanakan untuk meneliti puratan ideal blower pada mesin pengupas kopi tipe Hammer mill. 


\section{2. Pengolahan Data}

Keseluruhan data yang diperoleh dengan menggunakan metode-metode diatas, lalu diolah dengan cara berikut:

a. Seleksi data, yaitu menempatkan data pada klasifikasinya menurut kerangka bahasan

b. Klasifikasi data, yaitu menempatkan data pada klasifikasinya menurut kerangka bahasan

c. Penyusunan data, yaitu menempatkan data menurut kerangka bahasan dengan susunan yang sistematis

\section{3. Analisis Data}

a. Analisa kualitatif

Yaitu menguraikan data dalam bentuk kalimat yang jelas menurut bidang masing-masing, sehingga mudah dipahami dan memberi ati terhadap data.

b. Analisa kuantitatif

Yaitu menguraikan data dalam bentuk angka-angka atau pembobotan yang jelas sesuai dengan kegunaannya, sehingga mudah dipahami dan memberikan arti terhadap data.

\section{4. Lokasi Penelitian}

Penelitian ini dilaksanakan Desa Talang Padang Kabupaten Tanggamus serta untuk mendapatkan hasil penelitian yang diharapkan, maka penelitian ini akan meneliti putaran ideal blower pada mesin pengupas kopi tipe hammer mill.

\section{BAB IV. HASIL PENELITIAN}

\subsection{Data Mesin Pengupas Kopi Tipe Hamer Mill}

Mesin pengupas kopi tipe Hammer mill yang ada menggunakan sistem pukulan dalam memecahkan biji kopi. Kemudian kulit kopi akan langsung dipisahkan dengan sistem hisap oleh blower, sementara biji kopi akan turun ke penadah kopi.

\subsection{SPESIFIKASI MESIN}

\section{PENGUPAS KOPI TIPE}

\section{HAMMER MILL}

Data teknis

Tipe : Hammer mill 220 volt

Tenaga Penggerak : Elektro motor

110 volt / 220 volt

Panjang : $110 \mathrm{~cm}$

Lebar : $70 \mathrm{~cm}$

Tinggi: $140 \mathrm{~cm}$

Kapasitas \& Kupas : 90 kg/jam

kopi gelondongan

kering (Kadar air ideal 12\%)

Konstruksi : Logam

Tenaga Pemukul : Karet 72 buah

(75-So ahare)

Proses Pemukul : 2000rpm

Pemakai Tenaga : 1 orang

Berat Mesin : $150 \mathrm{~kg}$ 


\subsection{Persiapan Percobaan}

Untuk percobaan proses pemisahan biji dan kulit, peneliti mendapat kebijaksanaan dibantu oleh tenaga mekanik dan beberapa orang yang telah melakukan persiapan-persiapan sebagai berikut:

1. Persiapan mesin percobaan:

- Tipe mesin : Hammer Mill

- Rangka mesin : Terbuat dari baja

- Organ kerja : Corong penghisapblower dan penadah (bagian - bagian mesin)

- Penggerak : Motor listrik $1 \mathrm{Hp}$ dengan putaran $1476 \mathrm{rpm}$, tegangan 220 volt, pulli dan sabuk-V untuk pulli diambil sebanyak 7 buah dengan masingmasing ukuran pulli penggerak = $59 \mathrm{~mm}$ dan $93 \mathrm{~mm}$, pulli yang digerakkan blower, 93 mm, 102 $\mathrm{mm}, 188 \mathrm{~mm}, 127 \mathrm{~mm}$ dan 141 $\mathrm{mm}$.

2. Alat-alat ukur:

- Stop Watch

- Neraca

3. Bahan percobaan: kopi gelondongan sebanyak $1 \mathrm{~kg}$. Percobaan ini dilakukan dengan menggunakan variabel kapasitas kopi yang dijatuhkan dalam waktu tertentu. Dalam hal ini penulis mengambil sampel sebanyak 3 kapasitas yaitu:

a. 1000 gr per $1 / 2$ menit (30 detik)

$$
=120 \mathrm{~kg} / \mathrm{jam}
$$

b. 1000 gr per $2 / 3$ menit (40 detik) $=90 \mathrm{~kg} / \mathrm{jam}$

c. $\quad 1000$ gr per 1 menit (60 detik) $=60 \mathrm{~kg} / \mathrm{jam}$

Dalam percobaan ini variable putaran blower yang diambil peneliti menggunakan perbandingan pulli yang ada dipasaran (seperti tersebut diatas) untuk menghasilkan variasi putaran ynag didapat adalah 8 jenis putaran.

Perhitungan Teoritis:

1. Diketahui : $\mathrm{n}_{1}=$ Putaran poros motor $\quad=1476 \mathrm{rpm}$

$$
\begin{aligned}
& \mathrm{n}_{2} \quad=\text { Putaran poros } \\
& \text { pemukul }=2000 \mathrm{rpm} \\
& \mathrm{d}_{1}=\text { Diameter pulli } \\
& \text { motor } \quad=300 \mathrm{~mm} \\
& \mathrm{~d}_{2} \quad=\text { Diameter pulli } \\
& \text { pemukul }=1476 \mathrm{rpm}
\end{aligned}
$$

data tersebut dihasilkan dari $\mathrm{n}_{\text {motor }}$ dan diameter kedua pulli. Dengan demikian, jika dimasukkan dalam tabel 1 sebagai berikut: 
Tabel 1. Putaran poros motor, putaran poros pemukul dan diameter pulli motor dan diameter puli pemukul

\begin{tabular}{|l|l|l|l|l|l|}
\hline $\begin{array}{l}\mathrm{D}_{3}(\mathrm{~mm}) \\
\mathrm{D}_{2}(\mathrm{~mm})\end{array}$ & 93 & 102 & 118 & 127 & 141 \\
\hline 59 & 1268,82 & 1156,86 & 1000 & 929,13 & 836,88 \\
\hline 93 & & & 1576,27 & 1464,57 & 1319,14 \\
\hline
\end{tabular}

Keterangan: Putaran blower yang merupakan putaran blower pada mesin pengupas kopi

\subsection{Prosedur Percobaan}

Percobaan ini dilaksanakan 8 kali untuk 1 sampel. Karena jumlah sampelnya ada 3 dengan kapasitas yang berbeda, maka keseluruhannya 24 kali percobaan.

Prosedur percobaan yang dilakukan diuraikan dibawah ini. Prosedur percobaan pemisahan dan kulit kopi adalah:

1. Siapkan perlengkapan pecobaan (alat, bahan dan saran pendukung).

2. Pasang pulli sesuai dengan putaran blower yang diinginkan.

3. Hidupkan motor listrik/mesin.

4. Tuangkan kopi gelondongan dalam waktu sesuai dengan sampel yang dicoba, gunakan stop watch sebagai penunjuk waktu.
5. Setelah selesai, ambil biji dan kulit dari penadah masing-masing, kemudian pisahkan antara kulit dan biji masing-masing pendagah dengan pengayak

6. Timbanglah dengan menggunakan neraca yang telah disediakan. Untuk pertama ambil biji dari penadah biji dan ditimbangkan, lalu ambil kulit yang ada dari biji penadah

7. Catatlah hasilnya tiap-tiap percobaan

8. Setelah semua selesai dapat diganti pulinya jika mencoba putaran yang lain atau diganti pulli seperti semula jika seluruh percobaan selesai.

\subsection{Hasil Penelitian}

Dari percobaan yang dilakukan peneliti, maka didapat hasil sebagai berikut:

Tabel 2. Kapasitas (K) 1000 gram per 1 menit $(60$ detik $)=60 \mathrm{~kg} / \mathrm{jam}$

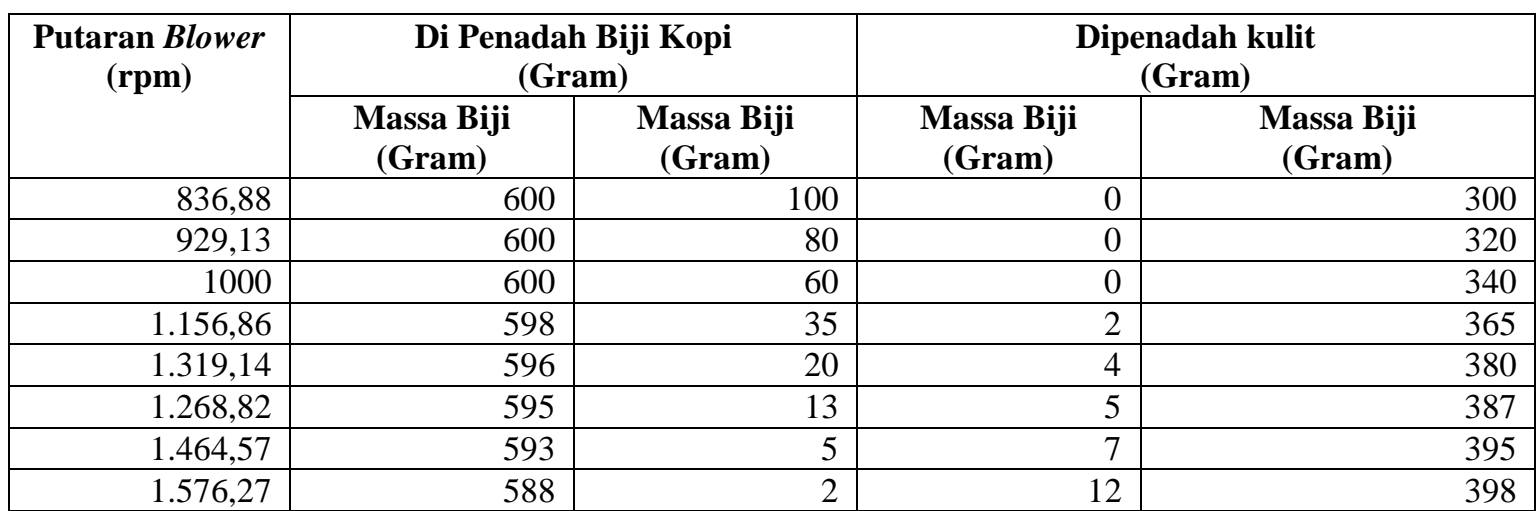


Tabel 3. Kapasitas $(K)=1000$ gram per $2 / 3$ menit $(40$ detik $)=90 \mathrm{~kg} / \mathrm{jam}$

\begin{tabular}{|c|c|c|c|c|}
\hline \multirow[t]{2}{*}{$\begin{array}{l}\text { Putaran Blower } \\
\text { (rpm) }\end{array}$} & \multicolumn{2}{|c|}{$\begin{array}{c}\text { Di Penadah Biji Kopi } \\
\text { (Gram) }\end{array}$} & \multicolumn{2}{|c|}{$\begin{array}{c}\text { Dipenadah kulit } \\
\text { (Gram) }\end{array}$} \\
\hline & $\begin{array}{l}\text { Massa Biji } \\
\text { (Gram) }\end{array}$ & $\begin{array}{c}\text { Massa Biji } \\
\text { (Gram) }\end{array}$ & $\begin{array}{l}\text { Massa Biji } \\
\text { (Gram) }\end{array}$ & $\begin{array}{c}\text { Massa Biji } \\
\text { (Gram) }\end{array}$ \\
\hline 836,88 & 600 & 125 & 0 & 275 \\
\hline 929,13 & 600 & 95 & 0 & 305 \\
\hline 1000 & 600 & 67 & 0 & 333 \\
\hline $1.156,86$ & 599 & 40 & 1 & 360 \\
\hline $1.319,14$ & 598 & 21 & 2 & 379 \\
\hline $1.268,82$ & 598 & 15 & 2 & 385 \\
\hline $1.464,57$ & 597 & 6 & 3 & 394 \\
\hline $1.576,27$ & 587 & 2 & 3 & 398 \\
\hline
\end{tabular}

Tabel 4. Kapasitas $(K)=1000$ gram per $1 / 2$ menit $(30$ detik $)=120 \mathrm{~kg} / \mathrm{jam}$

\begin{tabular}{|r|r|r|r|r|}
\hline \multirow{2}{*}{$\begin{array}{c}\text { Putaran Blower } \\
\text { (rpm) }\end{array}$} & \multicolumn{2}{|c|}{$\begin{array}{c}\text { Di Penadah Biji Kopi } \\
\text { (Gram) }\end{array}$} & \multicolumn{2}{c|}{$\begin{array}{c}\text { Dipenadah kulit } \\
\text { (Gram) }\end{array}$} \\
\cline { 2 - 5 } & $\begin{array}{c}\text { Massa Biji } \\
\text { (Gram) }\end{array}$ & $\begin{array}{c}\text { Massa Biji } \\
\text { (Gram) }\end{array}$ & $\begin{array}{c}\text { Massa Biji } \\
\text { (Gram) }\end{array}$ & \multicolumn{2}{c|}{$\begin{array}{c}\text { Massa Biji } \\
\text { (Gram) }\end{array}$} \\
\hline 836,88 & 600 & 150 & 0 & 250 \\
\hline 929,13 & 600 & 120 & 0 & 250 \\
\hline 1000 & 600 & 105 & 0 & 310 \\
\hline $1.156,86$ & 599 & 90 & 1 & 322 \\
\hline $1.319,14$ & 598 & 78 & 2 & 320 \\
\hline $1.268,82$ & 598 & 50 & 2 & 385 \\
\hline $1.464,57$ & 597 & 80 & 3 & 3 \\
\hline $1.576,27$ & 585 & 15 & 3 & \\
\hline
\end{tabular}

Keterangan: Putaran blower yang merupakan putaran blower pada mesin pengupas kopi tipe Hammer mill yang berkapasitas 90 kg/jam

Setelah mengadakan percobaanpercobaan pada bagian-bagian pemisah antara biji dan kulit, mesin pengupas kopi tipe Hammer mill yang ada, maka peneliti memberikan kesimpulan yaitu dari ketiga kapasitas diatas, maka kapasitas (K) “90 kg/jam lebih baik dibandingkan kapasitas yang lainnya.

\subsection{Perhitungan Sabuk (Belt)}

Dalam mendesain sabuk penggerak (Belt drive), sesuai dengan kondisi kerja dan keperluannya, maka peneliti mengambil sabuk-V sebagai sabuk penggerak.

\subsection{Bantalan (Bearing)}

Untuk bantalan yang ada sesuai pada mesin yaitu tipe bantalan gelinding dengan ukuran d2s (diameter poros pemukul $)=25 \mathrm{~mm}$. Jadi ukuran bantalan

- Diameter dalam (d) $\quad=35 \mathrm{~mm}$

- Diameter luar (D) = $=52 \mathrm{~mm}$

- Lebar bantalan (B) = $\quad 15 \mathrm{~mm}$

- Radius (r) $\quad=1,5 \mathrm{~mm}$ 


\section{Kesimpulan Dan Saran}

\subsection{Kesimpulan}

1. Putaran blower yang ideal untuk mesin pengupas kopi tipe Hammer mill yaitu 1.576,27 rpm berdasarkan penelitian yang telah dilakukan yaitu terhadap 1000 gram biji dan kulit kopi, maka pada penadahan biji terdapat kulit sebanyak 2 gram sedangkan pada penadah kulit terdapat biji sebanyak 3 gram.

2. Kapasitas pengupasan kulit tetap yaiut $90 \mathrm{~kg} / \mathrm{jam}$

3. Dengan berubahnya putaran blower, maka diameter pulli yang digunakan adalah:

Diameter pulli motor $(\mathrm{dp})=300 \mathrm{~mm}$ Diameter pulli pemukul $(\mathrm{Dp})=221,4$ $\mathrm{mm}$

Diameter pulli pemukul $\left(\mathrm{d}_{2}=93 \mathrm{~mm}\right.$ Diameter pulli blower $\left(\mathrm{d}_{3}\right)=118 \mathrm{~mm}$

4. Untuk poros tetap menggunakan yang ada, karena poros tersebut aman digunakan dengan poros yang ada yaitu:

Diameter poros motor $(\mathrm{ds})=18 \mathrm{~mm}$ Diameter poros pemukul $\left(\mathrm{ds}_{2}\right)=$ $25 \mathrm{~mm}$

Diameter poros blower $\left(\mathrm{d}_{\mathrm{s} 3}\right)=20$ $\mathrm{mm}$

\subsection{Saran}

1. Agar putaran blower tipe Hammer mill yang ada, dapat dirubah sesuai hasil percobaan yang telah dilakukan.

2. Agar mesin tetap berada dalam kondisi baik, maka mesin senantiasa harus dirawat sesuai dengan ketentuan yang telah ditentukan.

\section{DAFTAR PUSTAKA}

Arismunandar Wiranto, Heiza Salto, 2011, Penyegaan Udara, Institut Teknologi Bandung.

M.F. Spott S, 2010, Design of Machine Element, Fifth Edition

N. Rudenko, 2014, Materials Handling Equipment, First Published Edition

Sularso Suga, Kiyokatsu, 2014, Dasar Perencanaan dan Pemelihaaan Elemen Mesin, Cetakan VIII, PT. Paradnya

Takeshi Satu, N. Sugiaro, 2012. Mengebor Mesin Menurut Stontor, ISO G 